\title{
RESENHA
}

\section{DENUNCIAR E ANUNCIAR: A MENINA QUE UTILIZOU AS REDES SOCIAIS PARA ENFRENTAR O DESCASO COM A ESCOLA}

DOI: http://dx.doi.org/10.1590/2236-3459/71697

\author{
Juliana dos Santos Rocha \\ Pontifícia Universidade Católica do Rio Grande do Sul, Brasil.
}

$\cos 80$

FABER, Isadora. Diário de Classe - a verdade: a história da menina que está ajudando a mudar a educação no Brasil. Belo Horizonte: Editora Gutenberg, 2014.

$64 \begin{aligned} & \text { ue país é esse?". Questiona o título de uma conhecida música, de } \\ & \text { Renato Russo, escrita no final da década de 1970, lançada na década } \\ & \text { seguinte e utilizada para denunciar a corrupção no Brasil. Na época, a }\end{aligned}$ música foi fortemente utilizada com este intuito: denúncia. No cenário atual, as redes sociais são um dos recursos mais utilizados para este fim. A exemplo disso, o livro Diário de Classe, lançado no ano de 2014, conta a história da jovem Isadora Faber e suas relações e ações na escola, a partir da criação de uma página no Facebook, chamada de "Diário de Classe", com o intuito de denunciar questões importantes e recorrentes que ocorriam em sua escola. Na época, a menina tinha 13 anos e frequentava a Escola Básica Municipal Maria Tomázia Coelho, de Florianópolis, no Estado de Santa Catarina. O livro é composto por 21 capítulos, totalizando 268 páginas.

Isadora conta que estudou todo o Ensino Fundamental na mesma escola e tudo parecia tranquilo até a quinta série. Nesse momento, a família obteve uma bolsa para sua irmã do meio em uma escola privada. A discrepância dos conteúdos dados nas duas escolas, nas mesmas séries, foi percebida rapidamente. Ela conta que sua irmã chegou um dia em casa dizendo que o professor de inglês da nova escola havia falado somente 
em inglês na aula e ela não havia entendido nada, que o professor de matemática passara uma lição da qual ela não havia aprendido o conteúdo. Entretanto, ressalta que inicialmente não fazia uma crítica séria ao sistema de educação pública; "naquela época eu tinha o pensamento medíocre, mas infelizmente comum: achava que, como a escola era de graça, nós não podíamos e nem tínhamos o direito de reclamar", relata (FABER, 2014, p. 35). Foi ao visitar a escola da irmã que Isadora começou a perceber a precariedade da escola em que estudava, que tinha um espaço físico muito maior, porém totalmente descuidado.

O livro e a fanpage denunciam problemas como choques elétricos, faltas recorrentes de professores, professores que não dão aula, falta de ventiladores, filas enormes em um único bebedouro, portas e janelas quebradas. Isadora relata que todos reclamavam, mas ninguém fazia nada. A primeira providência de Isadora foi convidar uma amiga e conversar com o professor de matemática, pois não estavam conseguindo aprender a matéria e havia muita bagunça na aula. Nenhuma providência. A segunda etapa foi buscar a direção da escola, sobre a aula de matemática, na qual o professor não dava aula e havia muita bagunça, e sobre o espaço físico, o que estava estragado etc. Nada! De acordo com a autora, foram muitas tentativas de resolver o assunto com a direção, que não tomou nenhuma providência.

Foi então que a irmã de Isadora, Ingrid, falou sobre a história da escocesa Martha Payne, que aos 9 anos havia denunciado o problema da alimentação escolar e, assim, mobilizado toda a comunidade para resolver a questão ${ }^{1}$. Inspirada na história da estudante de 9 anos, Isadora resolveu criar a página no Facebook, onde fazia postagens diárias comentando os absurdos que encontrava na escola, acompanhadas de registros fotográficos, para a qual contou com a colaboração de sua melhor amiga, Melina.

Em seguida, a página começou a ficar conhecida e entre alunos, professores e funcionários da escola. A autora não esperava tanta repercussão. Atualmente, a página tem mais de 600 mil seguidores, e não demorou para que a menina fosse reconhecida pela criação. De acordo com a autora, cerca de um mês após a publicação da página, chegaram a quase 2 mil seguidores e no mês de agosto, após um final de semana no qual o número de seguidores cresceu muito, começaram a chegar os jornalistas nacionais e ligações internacionais para entrevistá-la.

Entretanto, a repercussão não foi tão positiva quanto se pode pensar inicialmente. Isadora conta como foi perseguida pelos funcionários, professores e até pelos próprios colegas, na escola. Recebeu ameaças e represálias, teve a casa apedrejada, pressionando para que a página fosse tirada do ar. "Sofri agressões, represálias, ameaça de morte, calúnias, processos, perseguições”, diz ela (FABER, 2014, p. 23). Funcionários passaram nas salas de aula incitando os alunos a darem uma "lição" em Isadora, já que eles, como adultos, não poderiam, contou uma amiga em segredo à ela, por medo de também sofrer represálias.

Nesse sentido, entende-se que a adolescência socialmente concebida como uma fase universal e psicológica do desenvolvimento, pode influenciar para que esse sujeito seja visto na escola em uma perspectiva mais negativa, de oposição, de afronta (ROCHA, 2016), e não como um agente transformador e sujeito do seu processo de escolarização e

${ }^{1}$ Cf. http://neverseconds.blogspot.com.br/ 
aprendizagem. É importante ressaltar que essa perspectiva mais patologizante e estereotipada da adolescência foi construída historicamente e cristalizada pela psicologia ocidental, no século XX (OZELLA, 2003). Contudo, os agentes da educação, na atualidade, precisam compreender que trata-se de um sujeito histórico-cultural, que se constitui dialeticamente com a sociedade. Na escola ele é um dos sujeitos mais importantes, que precisa ser ativo no processo. Estes já eram os pressupostos da Escola Ativa e da Escola Nova, desde a segunda metade do século XIX, que começam a ser discutidas no Brasil na década de 1920, com o intuito de repensar a escola tradicional e propor uma educação mais flexível, que tem as relações como centralidade, nas quais os interesses e as experiências dos alunos são mote para a aprendizagem e para a construção da proposta curricular (LOURENÇO FILHO, 2002).

Apesar da pressão, Isadora não cedeu. Estava convicta que a denúncia seria uma forma, talvez a única naquele momento, de conquistar melhorias significativas para as solicitações de antemão ignoradas. Após tanta publicidade e apoio na fanpage - quase 200 mil seguidores - iniciaram as reformas na escola. A secretaria da educação publicou uma nota dizendo apoiar iniciativas como a da Isadora e a diretora assumiu a responsabilidade pela má administração, afirmando que não havia pressionado para que a página fosse tirada do ar, o que, de acordo com Isadora, é uma inverdade. A menina utilizou a página para postar as melhorias e buscar conscientizar os colegas para os devidos cuidados com o espaço público da escola. Aos poucos, a autora da página foi anunciando as conquistas e as novas possibilidades para as ações na escola se efetivarem, como por exemplo, a criação da Associação de Pais e Professores, a cobrança da entrega e regularização da prestação de contas da escola, o que possibilitaria a liberação de novas verbas.

Belloni (2007), infere que instituições como escola e família vem sendo fortemente penetradas pela mídia. É imperioso pensar acerca dos reflexos que esse movimento pode causar em tais instituições. O fato é que a participação da mídia na atualidade é inevitável, é necessário, sim, refletir como agir a partir dela. Nesse sentido, é importante lembrar que a mídia e as tecnologias não tem o papel apenas de informar, mas também de formar o cidadão, transmitindo sempre algum juízo de valor, uma compreensão específica do mundo e da sociedade etc. Utilizar as redes sociais como forma de transformação social, para campanhas de humanização, para denúncias de abusos dos mais variados tipos, preconceitos e discriminações pode ser uma forma de utilizar o "boom tecnológico" à favor de uma sociedade mais justa e igualitária. Já que é impossível negar ou mesmo frear essa expansão das tecnologias, então que a educação aprenda a utilizá-la para benefício próprio.

Isadora e o Diário de Classe se tornaram conhecidos. A menina, hoje, viaja o Brasil e o mundo participando de eventos culturais, debates sobre protagonismo infantil e mídias, lutas feministas por educação e liberdade, entre outros. O último capítulo do livro é dedicado às mudanças necessárias na educação, intitulado "Vamos mudar a educação no Brasil". Nesta seção a autora lembra de problemas como a violência, desrespeito para com professores e alunos, desvalorização da educação e, principalmente, a má gestão da educação na atualidade. Em tom conclusivo, salienta que a educação é "problema" de toda a sociedade. Sendo assim, é necessário que todos se engajem e lutem por educação de qualidade e para todos, utilizando os recursos disponíveis, como a internet, 
tendo vistas às mudanças efetivas.

Contudo, restam algumas perguntas que podem ser mote para reflexão na área da educação: como a escola pode abrir espaço para que o aluno seja agente transformador do espaço educacional? Não seria a escola muito mais atrativa e efetiva se os alunos tivessem voz ativa e fossem corresponsáveis pelo espaço educacional? Como lidar, enquanto aluno, professor ou funcionário com um caso semelhante a este? Qual seria sua reação? Como a escola pode utilizar as redes sociais para qualificar o processo de escolarização? Como envolver toda a comunidade escolar de forma efetiva? $E$, finalmente, como resolver os problemas de "minha" escola?

Obviamente, há muitas questões que são estruturais, que são do Estado, mas há outras que são simples e ficam esquecidas, muitas vezes. No que se refere às questões maiores, é necessário que haja controle social, sem ele sabe-se que pouco acontece no país. O que fazer, então? O que fazer agora?

\section{Referências}

BELLONI, Maria Luíza. O que é Mídia- Educação. São Paulo: Autores Associados, 2001.

LOURENÇO FILHO, Manuel Bergstrom. Introdução ao estudo da Escola Nova: bases, sistemas e diretrizes da pedagogia contemporânea. Rio de Janeiro: EdUERJ, 2002.

OZELLA, Sergio. A Adolescência e os Psicólogos: a concepção e a prática dos profissionais. In: OZELLA, Sergio. Adolescências Construídas: a visão da psicologia sócio-histórica. São Paulo: Cortez, 2003. p. 17-40.

ROCHA, Juliana S. O aprender como processo humano: os sentidos subjetivos produzidos por adolescentes em situação de vulnerabilidade social acerca da aprendizagem. 2016. 217f. Dissertação (Mestrado em Educação) - Programa de Pósgraduação em Educação, Pontifícia Universidade Católica do Rio Grande do Sul, Porto Alegre, 2016.

JULIANA DOS SANTOS ROCHA é Psicopedagoga. Mestre e doutoranda em Educação pela Pontifícia Universidade Católica do Rio Grande do Sul (Pucrs). Bolsista CAPES. Professora Convidada do Curso de Especialização em Psicopedagogia Clínica e Institucional da Pucrs. Pesquisadora do Núcleo de Pesquisa sobre Aprendizagem e Processos Inclusivos (Nepapi) e do Grupo de Pesquisa Formação Docente, Inclusão e Processos de Aprendizagem (FIPA). Endereço: Rua Pedro Velho, 248 - 90680-510 - Porto Alegre/RS - Brasil.

E-mail: juliana.rocha.001@acad.pucrs.br

Recebido em 06 de março de 2017.

Aceito em 15 de abril de 2017. 